\title{
Research on the Construction of Professional Accomplishment Development M-learning Platform for College Students
}

\author{
Tingwei Pan \\ Elementary Education College \\ Zaozhuang University \\ Zaozhuang, China
}

\begin{abstract}
With the development of science and technology, human's education means are continuously updated. At present, mobile learning (M-learning) is becoming a booster for the development of education, and especially it will have a profound influence on the means of higher education and vocational education. The mobile learning platform can greatly meet people's need for education in "Internet + " era, and it not only provides a broad space for continuing education, universal education and lifelong education, but also becomes a driving force for social development and progress. In the meantime, the learning places are no longer limited to schools and classrooms while mobile learning at anytime and anywhere will become an important learning form. But related researches show that mobile learning still has deficiencies in the aspects of resource requirement, curriculum setting and platform construction. Therefore, the research on the construction of professional accomplishment development M-learning platform for college students in this paper has a positive theoretical and realistic significance. This paper makes a research from the perspective of the current situation of college students' mobile learning, their professional accomplishment and the construction and application of mobile learning platform. Firstly, it makes analysis of the design principles and functions of $\mathrm{M}$-learning platform based on WeChat official platform, and divides platform functions into three parts: micro-class, micro-information and micro-forum. Secondly, it takes the college students in local university as the sample to carry out M-learning teaching practice. Thirdly, through the specific cases during teaching process, this paper makes analysis of the efficiency of college students using M-learning platform in five latitudes consisting of sample selection, benefit object, platform functions, teaching design and teaching effect, and also makes a vertical comparison combined with the study situation of other college students, so as to achieve multi valuable research data. Finally, it reflects on the system instabilities and rare curriculum resources, etc., in the practice process of M-learning platform, and hopes that, with the development of science and technology and promotion of $M$ learning mode, shortcomings and difficulties will be further improved.
\end{abstract}

Keywords-M-learning; college students; professional accomplishment development

\section{INTRODUCTION}

Today is a society with rapid development of science and technology that has promoted the continuous development of productivity and social economy and also affected people's work, study and life style. In recent years, with the development of $3 \mathrm{G}$ and $4 \mathrm{G}$ communication technologies, the popularization of mobile phones, especially intelligent mobile phones, has brought new feelings for learners to learn at anytime and anywhere.

M-learning is the abbreviation of mobile learning, which is its English name. It refers to the learning on the mobile learning platform by using communication equipment under the guidance of lifelong learning. At present, it mainly refers to an intelligent and personalized learning by mobile phone[1]. Firstly, mobile learning can help college students to obtain a wealth of knowledge from the rich network learning resources by mobile device so as to enhance their overall quality; and it also allows them to save time to put into social practice, achieving the purpose of applying what you have learned and following what you learn. Secondly, M-learning students can choose flexible learning methods. Introverted and inarticulate students can't express themselves well in the classroom teaching, but they can better show their strengths and thinking advantages in the mobile learning platform. Finally, Mlearning platform allows learners to choose their own learning content or learning time, and, according to the class situation, review the old or learn new knowledge, which makes learning more targeted and efficient.

Various mobile learning platforms provide a broad environment for universal education, lifelong education as well as continuing education, and provide impetus for social development and progress. Relevant research shows that there are still some deficiencies in resource requirements, curriculum and platform construction for mobile learning. This paper aims to explore a new teaching model based on professional accomplishment development M-learning platform. 


\section{ANALYSIS OF THE CONSTRUCTION OF PROFESSIONAL ACCOMPLISHMENT DEVELOPMENT M-LEARNING PLATFORM FOR COLLEGE STUDENTS}

WeChat official platform enables many businesses to carry out we-media activities via official accounts platform. For example, by applying for WeChat official service accounts, information push and product promotion, as well as some light application functions, can be realized. In addition, the government offices and departments also opened a WeChat official platform to realize the extension of government service functions. Many colleges in China also release campus information through WeChat official platform, and carry out learning exchanges, etc. [2].

\section{A. Design Principles of M-learning Platform Based on WeChat Official Platform}

The development of information technology makes the reform of the teaching mode of "cramming education" in colleges, and many colleges advocate the use of multimedia teaching, which is limited to a simple way to cast courseware and difficult to interact. The teaching platform based on WeChat official platform can integrate teaching resources with modern information technology closely so as to achieve the teaching purpose of colleges [3]. The construction of the Mlearning professional accomplishment development of WeChat official platform should give full consideration to its construction principles, which should be based on the characteristics of mobile phone functions and user's scattered time, etc.:

1) Diversity principle of learning resources on WeChat official platform:The stereotyped teaching mode and unchanged teaching style has been unable to meet the diversified social needs which can only be achieved by the comprehensive application of various teaching methods. Increasing the diversity of learning platform resources can attract more users' attention. It can provide learners with a flexible, diverse and lively learning way at anytime and anywhere through text and learners' favorite learning resources such as video and audio.

2) Simplicity principle of learning resources on WeChat official platform: Simplicity principle requires that the learning content should be short and pithy. The learning resources should not be too complicated, and even if it is a long article, it shall be split into a few knowledge points for WeChat information push [4].

3) “One-stop" principle of WeChat official platform: In addition to providing the main learning function, learning platform should also pay attention to entertainment and respect for learners' autonomy. Through the illustrated, rich and colorful one-stop platform, the learners can improve their learning efficiency and truly embodies edutainment, for it is a platform on which learners can chat, learn and discuss, realizing a better interaction between teachers and learners.

4) Low cost principle of WeChat official platform:The platform video courses must be limited in duration to reduce downloads, because too long video download time requires lots of download flow, which is suitable for online learning, but not for mobile learning. How to reduce the teaching cost and the cost of using WeChat official platform is a problem that must be seriously considered in the platform construction.

In addition, WeChat official platform shall possess friendly operation principle while also set up an extensible interface. The design principles for mobile learning have obvious similarity, and only when WeChat official platform meet these design principles can it provide guarantee to promote the application of mobile learning on professional accomplishment development.

\section{B. Function Analysis of M-learning Platform Based on WeChat Official Platform}

The M-learning platform should have a wide range of functions to promote teaching. Learners can register WeChat ID with their mobile phone number. After registering, they can use the platform to get the corresponding education resources, and upload their work through the platform or share it to "Moments". In order to ensure the realization of this function, this paper aims to study the WeChat official platform according to the teaching objectives. In the author's opinion, the M-learning of WeChat official platform shall meet the needs of the majority of learners to use education resources. In addition to the basic information push, it should also include a communication forum and wonderful boutique course display to facilitate learners for a diversified mobile learning. Through the investigation of college students, the created WeChat official platform based on the specialty characteristic has the following main functions:

1) Micro-classes:Micro-classes include science microclass, bilingual micro-class, fine art micro-class, music microclass and theory micro-class, etc. In each class, teaching materials with sounds, pictures and texts are published according to the teaching content for the students to use outside the classroom.

2) Micro-information: Micro-information releases multimedia information and information inside and outside campus, etc. WeChat official platform will carry out the information push actively every day to facilitate students to understand the latest learning content of the day. WeChat official platform can follow the tracks of students in the background to understand the reading and reproduced volume of the information.

3) Micro-forum: It's better for WeChat official platform to realize the communication between teachers and students, such as answering questions and handling disambiguation, as well as exchanging learning problems. Corporate certified WeChat official accounts can link website address to the forum. Personal WeChat platform that can't be authenticated can also achieve this kind of interaction through "Group Chat". The latter form is adopted in the application practice of this paper. Nowadays, the pace of life is fast and the classroom teaching has limitations, so neither teachers nor learners can carry out one-to-one communication and learning. The platform communication implemented by WeChat official 
platform can realize group chat and the push of learning materials. Students can ask teachers questions at anytime and anywhere, and get feedback on the questions from teachers in a relatively short period of time.

The "Moments" function in WeChat official platform is a good aid to the classroom learning mode. Through the functions "Favorite" and "Send to Chat" in "Moments", learners can realize the sharing of information and optimize the learning resources. Through the function "Share on Moments", learners can spread the knowledge to a broader space. The mutual learning between classmates and friends is conducive to the dissemination of knowledge and communication of information [5]. M-learning based on WeChat official platform is not only a learning resource carrier, but also a powerful platform to the rapid integration of network learning resources. The application of WeChat official platform is not our purpose but a method to improve the efficiency of learning and create the mode of teaching and learning.

\section{APPLICATION PRACTICE OF M-LEARNING PlatFORM OF PROFESSIONAL ACCOMPLISHMENT DEVELOPMENT FOR COLLEGE STUDENTS}

\section{A. Practice Summary}

The application of this study takes the classes of 2013 majored in preschool education of Elementary Education College in Zaozhuang University as the practice object. The preschool education major of Elementary Education College consists of six classes of 2013, eight classes of 2014 and six classes of 2015, in a total of 20 classes and 880 students, which is the largest local preschool education training base. Besides the independent teaching building, student dormitory and canteen for preschool education, the college is also equipped with an activity laboratory, a multi-functional lecture hall, a dance room, a computer room, a professional piano room as well as a voice laboratory for preschool education. Therefore, Elementary Education College is a modern college with wide Wi-Fi network coverage and advanced teaching equipment.

As for the application research, the practice object has unique advantages mainly reflected in the following aspects: Firstly, all the teachers of the Elementary Education College have high theoretical accomplishment and capability of education and teaching, and award-winning teachers of various high-quality courses account for more than $80 \%$ of all the course teachers. Secondly, the students in this college all major in pre-school education, so this practice has a rich practice base while it also can help students improve their learning ability and professional accomplishment. Thirdly, if the practice is successful, the teachers and students involved in this project implementation can sum up the teaching and learning experience, of which the application can be generalized for other course teaching in Zaozhuang University. Meanwhile, the inadequacies could be improved in the process of the project implementation, so as to promote the whole innovative reform process of teaching and learning.

\section{B. Platform Functions}

1) Information push: Managers use the WeChat official platform to send messages every day to students in the sample class. Before 6 p.m. of every Sunday evening, the manager shall send the learning content of all the courses for next week. Weekly learning content shall be pushed to the students' mobile phones in advance in the form of graphics and texts, so that students can understand next week's learning content and prepare lessons before class accordingly and achieve a targeted learning. Extract a sample of the 5th week, as shown in "Table I":

To know the various unequal relationships in life; To read the article with expression and make it into children's play; To appreciate Chinese traditional art and make artwork by various materials; To develop the ability of creativity; To improve the ability of child care.

TABLE I. PlatForm MASS INFORMATION IN THE 5TH WEEK

\begin{tabular}{|l|l|l|l|}
\hline \multicolumn{1}{|c|}{ Course } & \multicolumn{1}{|c|}{$\begin{array}{c}\text { Teaching } \\
\text { content }\end{array}$} & $\begin{array}{l}\text { Key and difficult } \\
\text { points }\end{array}$ & \multicolumn{1}{c|}{$\begin{array}{c}\text { After-class } \\
\text { assignments }\end{array}$} \\
\hline $\begin{array}{l}\text { Children's } \\
\text { literature }\end{array}$ & $\begin{array}{l}\text { My grandmother } \\
\text { and I }\end{array}$ & $\begin{array}{l}\text { Read the article with } \\
\text { expression }\end{array}$ & $\begin{array}{l}\text { Read the article } \\
\text { with expression }\end{array}$ \\
\hline $\begin{array}{l}\text { Mathemat } \\
\text { ics }\end{array}$ & $\begin{array}{l}\text { 2.3 Nature of the } \\
\text { inequality }\end{array}$ & $\begin{array}{l}\text { Application of } \\
\text { inequality nature }\end{array}$ & $\begin{array}{l}\text { Page 32 of after- } \\
\text { class exercises }\end{array}$ \\
\hline $\begin{array}{l}\text { Vocal } \\
\text { music }\end{array}$ & Ode to Joy & $\begin{array}{l}\text { Sing Ode to Joy } \\
\text { skillfully }\end{array}$ & Presentation \\
\hline Dance & Aerobics 9 & $\begin{array}{l}\text { Grand } \\
\text { Backward fall split, }\end{array}$ & Practice \\
\hline $\begin{array}{l}\text { Preschool } \\
\text { hygiene }\end{array}$ & $\begin{array}{l}1.4 \text { Children's } \\
\text { common diseases }\end{array}$ & $\begin{array}{l}\text { Prevention and } \\
\text { nursing of children's } \\
\text { common diseases }\end{array}$ & $\begin{array}{l}\text { Page 75 of after- } \\
\text { class exercises }\end{array}$ \\
\hline Handcraft & $\begin{array}{l}\text { Decorative } \\
\text { painting }\end{array}$ & $\begin{array}{l}\text { Make decorative } \\
\text { paintings from waste } \\
\text { materials }\end{array}$ & $\begin{array}{l}\text { Hand } \\
\text { decorative } \\
\text { paintings }\end{array}$ \\
\hline Piano & Bayer 31 & Rhythm & $\begin{array}{l}\text { Practice Bayer } \\
31\end{array}$ \\
\hline
\end{tabular}

2) Menu functions: In addition to the function of sending mass information, the learning platform also provides microclasses and other functions, which are displayed in a menu under the WeChat official platform, so that the students can browse the previous classic teaching contents and activities. The menu mainly includes micro-classes, micro-information as well as micro-forum, and the specific content is shown in the analysis of platform functions.

\section{Platform Application}

1) Case design: Through the investigation and analysis of teaching by WeChat official platform, the author takes "image processing" in computer culture foundation course as the teaching content to construct a micro-class based on WeChat official platform. This case selects the students from two classes as the object, and the relevant case is designed by combining the function features of mobile learning platform according to the actual needs of college students.

a) Student sample:The investigation shows that there are 75 students in the two classes (Class 4 of 2013 and Class 5 of 2013, both from preschool education). Among them, the percentage of the students having smartphones is $96.7 \%$, and the number of the students having and often using the WeChat 
accounts is 68 , moreover the mobile phone system of most students is above Andriod 2.0, which satisfies the teaching requirement.

b) Teaching process design: The computer culture foundation course itself is very practical and suitable for online learning and mobile learning. The design of M-learning case based on WeChat official platform includes several steps:

- Step 1: Micro-case development: The class requirements including video, documentation and PPT audio will be sent to the students' mobile phone in advance through the WeChat official platform.

- Step 2: Study first: Students will watch, read and listen, etc. through M-learning platform to learn about the class.

- Step 3: Class internalization: In class, students will conduct a cooperative learning and the teacher can provide one-to-one counseling to help students complete the new knowledge construction.

- Step 4: Evaluation feedback: Interactive exchanges, mutual evaluation of assignments as well as individual guidance for individual problems will be realized through "Group Chat".

In the pre-class teaching preparation, teachers will send learning content requirements and reference materials to student's mobile phone through the WeChat official platform, as shown in "Fig. 1". Even in the dormitory or in the washroom, students can prepare for the class in advance by learning the relevant materials. As for the confusions in learning process, students can seek help from online resources or WeChat official platform on which students can interact with teachers. Through this learning mode, students will not only make full use of time but also improve their learning efficiency.

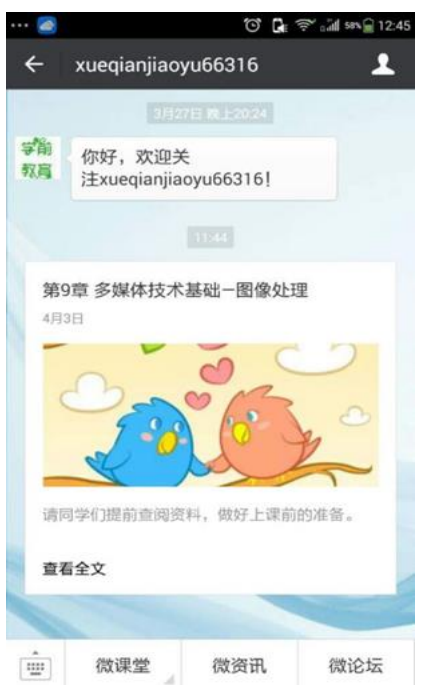

Fig. 1. Pre-class learning content push.

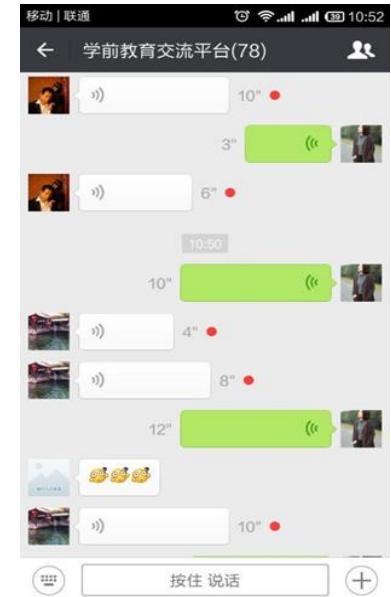

Fig. 2. Teacher-student interaction.

The learning content will be pushed to each student's WeChat before class, while the pre-class content for preparation and class teaching objectives will be arranged. Students will store the knowledge points in their mobile phones for pre-class preview and class use. Students will release their assignments on WeChat official platform and then teachers will send them feedback. Teacher-student interaction on WeChat official platform is shown in "Fig. 2".

2) Case analysis: Based on the application practice of Mlearning platform design in preschool education major and the materials of words and pictures collected from the system by the author, it can be figured out that $\mathrm{WeChat}$ official platform has improved students' enthusiasm to participate in the system learning, and the students also have developed the learning consciousness by applying M-learning platform, moreover the communication between teachers and students, students and students, has increased, as well students' learning autonomy has been enhanced. According to the application status of the samples, over $85 \%$ of the students can learn through the micro-classes on the WeChat official platform, with over $90 \%$ assignments completed, so the teaching effect is obvious.

According to the statistical tool on the platform and combined with the actual investigation, the relevant data are obtained, and the statistical analysis results are shown in "Table II". 
TABLE II.

ANALYSIS OF PLATFORM APPLICATION

\begin{tabular}{|c|c|c|c|}
\hline Item & Data & & Analysis \\
\hline Average daily login & 126 students per day & \multirow{3}{*}{\multicolumn{2}{|c|}{$\begin{array}{l}\text { Login is normal, students' enthusiasm is high. Maximum daily login appears when the teachers release } \\
\text { assignments while minimum daily login appears on the weekend. It is proved that the teachers' guidance } \\
\text { plays an important role in the platform application. It is essential for teachers to guide the students to apply } \\
\text { the platform. }\end{array}$}} \\
\hline Maximum daily login & 183 students & & \\
\hline Minimum daily login & 14 students & & \\
\hline \multicolumn{2}{|c|}{ Mass information average browsing amount } & 89 times per message & $\begin{array}{l}\text { Mass information browsing amount is very large, indicating the importance of } \\
\text { active push. }\end{array}$ \\
\hline \multicolumn{2}{|c|}{ Module of maximum browsing amount } & Fine art micro-class & \multirow{3}{*}{$\begin{array}{l}\text { Skill courses like art and music have a huge browsing amount, which reflects the } \\
\text { students' emphasis on skill learning. Module of maximum video click rate is } \\
\text { teaching videos in music micro-class, which shows that students pay more } \\
\text { attention to the study of music courses. }\end{array}$} \\
\hline \multicolumn{2}{|c|}{ Module of minimum browsing amount } & Theory micro-class & \\
\hline \multicolumn{2}{|c|}{ Module of maximum video click rate } & Music micro-class & \\
\hline \multicolumn{2}{|c|}{ Micro-forum participation amount } & $35 \mathrm{stu}$ & $\begin{array}{l}\text { Small participation amount in the forum indicates that students are not accustomed } \\
\text { to this communication. }\end{array}$ \\
\hline
\end{tabular}

Through the experiment and analysis towards the five latitudes including learning content, students' learning autonomy, teachers' workload, benefit object as well as teaching effect, and combined with the longitudinal comparison with other students' learning situation, it is concluded that the comparison between the platform application effect and traditional single teaching mode, as shown in "Table III":

TABLE III. COMPARISON OF TRADITIONAL CLASS AND EXPANDING CLASS

\begin{tabular}{|l|l|l|}
\hline \multicolumn{1}{|c|}{ Item } & Traditional class & $\begin{array}{l}\text { Expanding class based on } \\
\text { M-learning platform }\end{array}$ \\
\hline Learning content & Books & Multimedia and online \\
\hline Learning autonomy & Classroom & $\begin{array}{l}\text { Coverage area of Wi-Fi or } \\
\text { network }\end{array}$ \\
\hline Teachers'workload & Manual approval & $\begin{array}{l}\text { automatic approval and } \\
\text { statistics online }\end{array}$ \\
\hline Benefit object & $\begin{array}{l}\text { Students attending } \\
\text { class }\end{array}$ & $\begin{array}{l}\text { Students or others on } \\
\text { WeChat official platform }\end{array}$ \\
\hline Teaching effect & General & Excellent \\
\hline
\end{tabular}

The M-learning platform is jointly constructed by teachers who provide resources in pre-school education major. These teachers have made full preparation, so the learning contents are more controllable and targeted, applicable for college students of Zaozhuang University to cultivate and improve their learning ability and professional skills. Therefore, in the process of teaching and practice, teachers can give prompt reply in view of students' questions. The students accepting application feedback investigation agree that the M-learning platform corrects the bad habits of using mobile phones and also makes the students take full advantage of their spare time to improve their professional ability.

\section{APPLICATION EFFECT ANALYSIS OF THE}

\section{CONSTRUCTION OF PROFESSIONAL ACCOMPLISHMENT}

DEVELOPMENT M-LEARNING PLATFORM FOR COLLEGE STUDENTS

The results of platform application analysis show that: The application of this platform makes knowledge expandable, breaks the limitations of classroom teaching, and greatly enhances students' learning autonomy inside and outside the classroom. There are also some obstacles about M-learning platform. Therefore, combined with the above application research and based on the M-learning platform, the experience feedback of the construction of professional accomplishment development platform for pre-school education is as follows:
The template is designed so that author affiliations are not repeated each time for multiple authors of the same affiliation. Please keep your affiliations as succinct as possible (for example, do not differentiate among departments of the same organization). This template was designed for two affiliations.

\section{A. Little Content and Single Form}

Confined to the limitations of current college micro-class classroom and the uneven multimedia technologies of the teachers, multimedia learning resources such as videos and pictures are relatively fewer on M-learning platform.

\section{B. More Theory Courses, Fewer Video Courses}

Theory courses are relatively richer in teaching resources while some skill courses such as dance creation, solfeggio, and kindergarten activity design are relatively fewer and remain to be expanded.

\section{Personal WeChat Official Accounts without Real-name Authentication}

Many functions of WeChat official platform cannot be used, which limits the teaching practice on platform. However, the WeChat official platforms for enterprises and units have better application value.

\section{Further Guidance for Students' Application Enthusiasm}

The object of the application practice is five-year consistent college students, thus their enthusiasm for learning and good learning habit need to be further strengthened.

\section{CONCLUSION}

Learning is a process of continuity and persistence and also a process of subtle transition; it emphasizes the establishment of human and external relations. Therefore, the learning focus is not in the memory of learning content itself, but in developing a good learning habit. The learning based on WeChat official platform is an application of a new learning model facing the Internet era, so the display of its teaching results is a long-term process. The author has carried out a thorough study from the design of platform content, the collection and arrangement of resources, as well as information push, etc. according to the learning situation of students, this practice has a certain effect, but there are still many problems such as a unstable system and shortage of curriculum resources 
for the platform in the process of practice. It is hoped that the above problems will be alleviated and further improved with the development of science and technology and the promotion of mobile learning mode.

\section{REFERENCES}

[1] Wang Ping. Analysis of Support Functions and Design Principles of Mobile Learning Based on Wechat[J]. Journal of Distance Education,2013(6): 38.

[2] Gao Runqing. Reform Research of University Preschool Education Curriculum - based on Kindergarten Teacher Professional standards [J].. Curriculum, Teaching Material and Method, 2013(07)

[3] Xue Shuangfen. Specific Application of WeChat in University Education [J]. Journal of New Curriculum Learning. Volumes 2, 2015,(2): 28-29.

[4] Fang Bei Studio. Best Practices for WeChat Official Platform Development [M].Beijing: China Machine Press, 2014: 1-2..

[5] Wu Dan. Feasibility Study of WeChat Used in Classroom Teaching [J], China Information Technology Education, 2015(9): 85-87. 